\title{
A PÓS-GRADUAÇÃo EM ENFERMAGEM EM SAÚdE COLETIVA: O DESAFIO DA CONSTRUÇÃO CONJUNTA DO CONHECIMENTO
}

\author{
Emiko Yoshikawa Egry*
}

EGRY, E.Y. A pós-graduaçáo em enfermagem em saúde coletiva: o desafio da construção conjunta do conhecimento. Rev.Esc.Enf.USP, v.30, Número Especial, p.59-62, dez. 1996.

Descreve-se a constituição da Pós-Graduação em Enfermagem em Saúde Coletiva na Escola de Enfermagem da USP. São destacados os marcos teóricofilosóficos que dão base ao Programa, as disciplinas que o compõem e uma breve apreciação da sua trajetória de implementação.

UNITERMOS: Saúde coletiva. Enfermagem. Pós-Graduação em Enfermagem em saúde coletiva.

A constituição oficial do Departamento de Enfermagem em Saúde Coletiva, em fevereiro de 1987, sob a égide da saúde coletiva enquanto concepção, trouxe, além de outros desafios, a necessidade da qualificação dos enfermeiros neste campo do saber, para suprir a demanda departamental de renovação do seu corpo docente, assim como para responder às demandas nacionais, requeridas por força do movimento da reforma sanitária que, pouco mais tarde, traduzir-se-ia em força constitucional. Assim, ao definir as diretrizes de qualificação docente, foi visualizada a constituição de uma área de concentração em enfermagem em saúde coletiva, junto ao Programa de Pos-graduação, nivel de Mestrado, da Escola de Enfermagem da Universidade de São Paulo.

A tarefa de abertura da área de concentração demandou cerca de três anos de discussão intensa das docentes do Departamento de Enfermagem em Saúde Coletiva da EEUSP, além dos trâmites formais dentro da Escola e da Universidade. No primeiro formato haviamos previsto a constituição de 3 disciplinas obrigatórias da área de concentração, com duração de um semestre cada uma. Ao final da tramitação formal, o Programa havia se transformado para dar lugar a duas disciplinas obrigatórias semestrais, com doze créditos cada uma. Assim, antes

\footnotetext{
* Professora Associada do Departamento de Enfermagem em Saude Coletiva da Escola de Enfermagem da Universidade de São Paulo. Livre-Docente em Enfermagem em Saude Coletiva, Doutor em Saude Pública e Mestre em Enfermagem. Coordenadora da Área de Concentraçăo Enfermagem em Saúde Coletiva do Curso de P6s-Graduação em Enfermagem, nível de Mestrado, da Escola de Enfermagem da Universidade de São Paulo. E-mail: emiyegry@usp.br.
} 
mesmo de se iniciar, a estrutura da Área foi modificada, novamente, cuja composição passou para duas disciplinas obrigatórias de área de concentração, de 12 créditos (ENS I e ENS II), acrescidas de mais duas disciplinas eletivas de 8 créditos cada uma (TASC e MISC). Ainda, diante da necessidade de aprofundamento em termos de investigação científica foi aberta mais uma disciplina de 1 crédito (TISC). São elas:

\section{Enfermagem em Saúde Coletiva I - ENS I}

Propicia a análise crítica da gênese e do desenvolvimento histórico da estrutura social, do sistema de saúde, do saber e das práticas de saúde coletiva e de enfermagem. Possibilita a elaboração de projetos de intervenção para a transformação da prática de enfermagem.

\section{Enfermagem em Saúde Coletiva II - ENS II}

Busca o desenvolvimento e a implementação de projetos de intervenção para a transformação da prática de enfermagem em saúde coletiva, bem como a reinterpretação dessas intervenções nos processos de trabalho em saúde coletiva, fundamentados na analise dos diferentes referenciais teóricos que embasam os processos de trabalho em saúde coletiva e de enfermagem nessa área.

\section{Temas Avançados em Saúde Coletiva -TASC}

Trata do aprofundamento e estudo de algumas das principais expressões do processo saúde-doença em saúde coletiva e de modelos assistenciais vigentes, tendo como eixo de discussão as políticas públicas e de saúde. Culmina com a elaboração de uma monografia individual que recupera historicamente o desenvolvimento de um dos temas apresentados.

\section{Metodologia da Investigação em Saúde Coletiva - MISC}

Busca encaminhar a reflexão sobre a construção do saber em saúde coletiva, por meio da apresentação, discussão e análise dos diferentes referenciais teóricometodológicos utilizados nos estudos de investigação. Ao mesmo tempo, possibilita a discussão e análise das propostas de projetos individuais de pesquisa - referentes as futuras dissertações e teses - favorecendo a sua elaboraçà ou o redimensionamento. 


\section{Tendência da Investigação em Enfermagem em Saúde Coletiva - TISC}

Possibilita o adensamento teórico e metodológico da investigaçào em enfermagem em saúde coletiva, através de análise crítica das investigações realizadas, articulando o método ao objeto de pesquisa. $O$ eixo de discussão é dado pelas necessidades de produção de conhecimentos na temática.

Sob a vertente teórico-flosofica privilegiada - materialismo histórico e dialético - os pressupostos básicos para garantir a coerência na operacionalização do nosso Programa foram definidos, a partir da compreensão de que:

1. a expressão do processo saúde-doença em saúde coletiva, bem como o desenvolvimento de políticas sociais e de saúde, são determinados socialmente;

2. as práticas em saúde coletiva e, especificamente as de enfermagem em saúde coletiva, são práticas sociais, manifestadas em diferentes processos de trabalho e, como tais, estão articuladas à estrutura da sociedade e à dinâmica das forças de seus grupos sociais:

3. os processos de trabalho no âmbito do ensino, da assistência e da investigação científica na saúde e na enfermagem comportam transformações historicamente determinadas e de caráter processual;

4. a construção do saber em saúde coletiva é um processo coletivo que tem como horizonte a transformação da realidade.

Antecedendo ao início das da primeira turma, foi realizado um seminário interno do grupo de docentes do Departamento, responsável pelo programa (PGENS), com a participação das Professoras Doutoras Semíramis Melani Mello Rocha e Maria Cecília Puntel de Almeida, ambras docentes experientes em programas de pós-graduação em enfermagem de saúde pública e pertencentes a Escola de Enfermagem de Ribeirão Preto da USP. As sugestões e críticas ao Programa foram incorporadas na medida de nossas possibilidades, assim como outras que foram sendo acrescidas ao longo da execução, pelos docentes convidados de outras instituições de ensino, tais como os da Escola Nacional de Saúde Pública, Universidade Estadual de Campinas, Universidade Estadual de Londrina, Faculdade de Saúde Pública da USP, Universidade de Brasilia, entre outras.

Desde a primeira turma que se iniciou em 1992 até hoje, a estrutura central da área permanece a mesma, tendo sofrido algumas alterações apenas no conteúdo programático. Foi nossa previsão realizar um amplo debate e redirecionamento da área por volta de seu quarto ano de existência.

Nesses anos de implementação da Área de Concentração, paralelamente o Departamento albergou e intensificou a sua participação no Programa de Pós- 
graduação, no nível de doutorado. Dessa forma pôde consolidar as linhas de investigação existentes e também a construção de linhas novas, originárias da articulação entre o saber constituído e as necessidades da prática da enfermagem em saúde coletiva. É preciso reafirmar que essa construção coletiva não está restrita ao âmbito do Departamento, pois a atuação intensa de docentes da Escola pertencente aos demais departamentos; na qualidade de ex-alunas de doutorado, têm possibilitado dar conta de um campo de conhecimento tão vasto. Nesta ação interdepartamental para ministração de disciplinas, orientação de pesquisa e assessoria metodológica, estamos tendo a oportunidade verdadeira de intercâmbio entre as diferentes ramificações que podem e devem construir a enfermagem em saude coletiva. Ademais, novos projetos interdisciplinares e interinstitucionais estão sendo descortinados, o que sem dúvida, trarão novas demandas para 0 adensamento do conhecimento.

No presente ano, ao encaminhar a quarta turma de ingressantes, é mais do que visível a necessidade de readequar o seu ensino, para dar conta da maior dinamicidade e amplitude na preparação de nossos pós-graduandos. Está previsto para o ano próximo a reorientação global da área de concentração, tanto na sua estruturação quanto nos conteúdos ministrados, face às críticas dos alunos, dos docentes que ministram e dos que se encarregam das orientações de pesquisa. Nessa avaliação, sem dúvida deverão ser contempladas as novas diretrizes, demandas e critérios de excelência da CAPES. Além disso, será fundamental debruçar mais intensamente sobre as formas e critérios de avaliação, considerando-se os parâmetros brasileiros e os internacionais, sem perder de vista a essencialidade do programa, no que concerne à enfermagem e à saúde coletiva.

EGRY, E.Y. Nursing collective health graduate program: the challenge to construction of knowledge. Rev.Esc.Enf.USP, v.30, Special Issue, p.59-62, dec. 1996.

The author describes the Nursing Collective Health Graduate Program developped by Nursing School of São Paulo University. The philosophical and theoretical framework which guide the program are detached.

UNITERMS: Collective health. Nursing. Graduate program. 